\title{
Diffuse tensor cardiac MRI evaluation of fiber architecture of athlete hypertrophic heart in vivo
}

\author{
Ming-Ting Wu ${ }^{1 *}$, Wen-Yih I Tseng ${ }^{2,3}$, Mao-Yuan M Su ${ }^{3}$, Van J Weeden ${ }^{4}$, Timothy G Reese ${ }^{4}$ \\ From 15th Annual SCMR Scientific Sessions \\ Orlando, FL, USA. 2-5 February 2012
}

\section{Background}

The fiber architecture adaption in physiological hypertrophy of the althete heart is still delusive. We aimed to use diffusion tensor cardiac MR (DT-CMR) to evaluate the tissue property and fiber architecture of elite athlete heart.

\section{Methods}

Eight elite athletes of Marathon runner (endurancetraining type), 8 of weight-lifter (strength-training type) and 8 ordinary style (medical interns) were enrolled. Each subject received a CMR study on a $1.5 \mathrm{~T}$ scanner including 1. cine SSPF of a stack of LV short axis for LV mass and function; 2 DT-CMR, ECG-gated stimulated echo diffuse EPI on three levels of LV. Diffuse tensor composed of 6 directions and $\mathrm{b}$ value $=300 \mathrm{~mm} 2 /$ sec. 3. phase-contrast flow measurement at ascending aorta for stroke volume. The data were compared between groups and correlated between the parameters.

\section{Results}

The myocardium showed no difference of mean diffusivity (MD) and fractional anisotropy between the groups. Weight lifter showed increase of stroke volume / BSA and LV mass / BSA as compared to runner and ordinary groups. The fiber architecture showed an increased proportion of right-handed helical fibers (mainly in the subendocardial zone) in runner and lifter equally, as compared to ordinary group. Putting all 24 subjects together, there was a linear regression between the proportion of right-handed helical fiber and LV mass $(R$ square $=0.38, \mathrm{p}=0.002$ ).

${ }^{1}$ Department of Radiology, National Yang Ming University, Taipei, Taiwan Full list of author information is available at the end of the article

\section{Conclusions}

DT-CMR revealed the physiological hypertrophy of athlete heart was mainly due to right-handed helical fibers. This underscores the important role of subendocardial fiber on the LV function.

\section{Funding}

N/A

\section{Author details}

'Department of Radiology, National Yang Ming University, Taipei, Taiwan. ${ }^{2}$ Center for Optoelectronic Biomedicine, National Taiwan University, Taipei, Taiwan. ${ }^{3}$ Department of Medical Imaging, National Taiwan University Hospital, Taipei, Taiwan. ${ }^{4}$ National Yang Ming University, Taipei, Taiwan.

Published: 1 February 2012

\section{doi:10.1186/1532-429X-14-S1-P170}

Cite this article as: Wu et al:: Diffuse tensor cardiac MRI evaluation of fiber architecture of athlete hypertrophic heart in vivo. Journal of Cardiovascular Magnetic Resonance 2012 14(Suppl 1):P170.

Submit your next manuscript to BioMed Central and take full advantage of:

- Convenient online submission

- Thorough peer review

- No space constraints or color figure charges

- Immediate publication on acceptance

- Inclusion in PubMed, CAS, Scopus and Google Scholar

- Research which is freely available for redistribution 


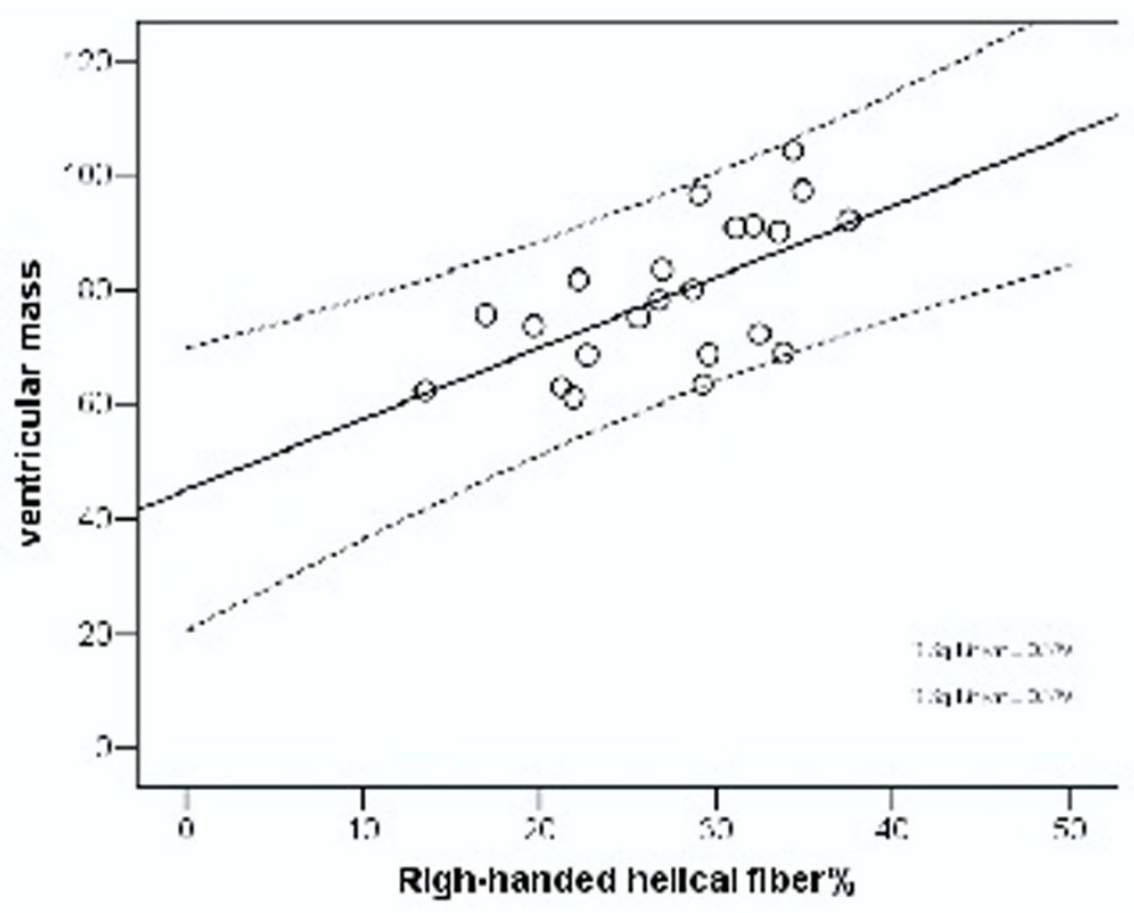

Figure 1 Regression between LV mass and right-handed helical fiber percentage across the 24 subjects. 